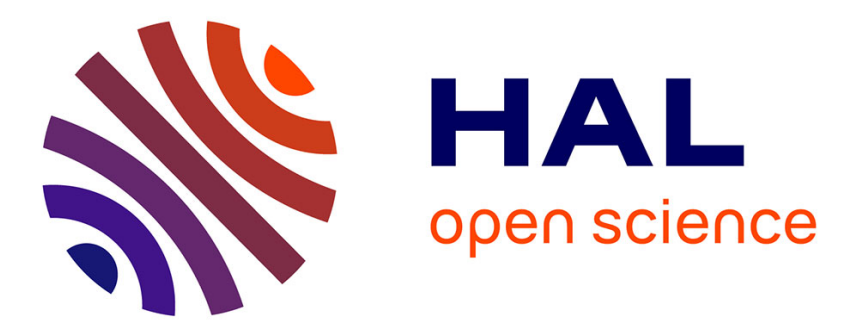

\title{
Aspects of growing langasite crystals and their properties
}

A. Gotalskaja, D. Drezin, G. Cherpoukhina, V. Bezdelkin, S. Schegolkova

\section{To cite this version:}

A. Gotalskaja, D. Drezin, G. Cherpoukhina, V. Bezdelkin, S. Schegolkova. Aspects of growing langasite crystals and their properties. Journal de Physique IV Proceedings, 1994, 04 (C2), pp.C2-201-C2210. 10.1051/jp4:1994226 . jpa-00252494

\section{HAL Id: jpa-00252494 https://hal.science/jpa-00252494}

Submitted on 1 Jan 1994

HAL is a multi-disciplinary open access archive for the deposit and dissemination of scientific research documents, whether they are published or not. The documents may come from teaching and research institutions in France or abroad, or from public or private research centers.
L'archive ouverte pluridisciplinaire HAL, est destinée au dépôt et à la diffusion de documents scientifiques de niveau recherche, publiés ou non, émanant des établissements d'enseignement et de recherche français ou étrangers, des laboratoires publics ou privés. 


\title{
Aspects of growing langasite crystals and their properties
}

\author{
A.N. GOTALSKAJA, D.I. DREZIN, G.N. CHERPOUKHINA, V.V. BEZDELKIN and \\ S.N. SCHEGOLKOVA
}

Scientific Research Institute "Fonon", 105023 Moscow, Krasnobogatyrskaya str. 44, Russia

\begin{abstract}
Synthesis technology and growing langasite crystal are described. The real structure and main types of defects are defined. Fundamental physical and piezoelectric properties of iangasite in comparison with properties of other piezoelectrics arm given. The application of these crystals in resonators and filters is mentioned.
\end{abstract}

For designing VCXOs, TCXos and fisters with a wide pass band while maintaining high stability and small insertion attenuation of these devices, the necessity arose in discovering new piezoelectrie crystals, having intermediate properties between those of quartz and lithium tantalate. They are berlinite and langasite. Growing berlinite erystals and its analogues, however, is connected with technological difficulties and with twinning problem [1]. Technological process of growing langasite crystais is simpler. It is grown up by Czochmalsky method in an air atmosphere at a temperature of $1470^{\circ} \mathrm{C}$. Langasite has no phase transitions up to the melting ooint and it does not need monodomenization compared with lithium niobate and lithium tantalate.

Langasite belongs to the group of compositions with the structure of calcium-galli im-germanium garnet (CGGG) and crystalizes in the same acentrie group as quartz $[2,3]$. Langasite crystal is a dielectric.

The purfose of cur worl: was to deveiop mass production technology of synthesis and growing ingasite crystals. Due to design of heat aesembly of crystallization chanbar we could grow lp langasite crystals 
with the diagonal diameter of $82 \mathrm{~mm}$ and the welght up to $2,0 \mathrm{~kg}$ (fig.1). The crystals were grown along the z-axis by employing equipment with the diameter control with the cylindrical part length up to $150 \mathrm{~mm}$. The crystal yield obtained was $60 \%$

The charge was prepared from oxides by using solid-state phase reaction via an intermediate composition - perovskite at a temperature of $1300^{\circ} \mathrm{C}$. Eased on the result obtained by differential thermal gravimetric analysis it was found that langasite phase appears over the temperature range above $1000^{\circ} \mathrm{C}$.

The features of langasite crystalization process are dissociation presence and evaporation of gallium oxide, crystalization front (CF) Inversion and facial growth.

Gallium oxide evaporation causes distortion of stoichiometric composition of the melt and deterioration of crystal quality. Gallium oxide dissociation contributes to platinum oxidation, its transfer to the melt and entering into the erystal as inclusions.

The most important condition for growing perfect crystals is obtalning a flat crystallisation front. Crystallization front inversion was observed in the process of conical part growth of the crystal. This causes excessive defect formation in the conical part of the crystal. It is recommended to choose such a rotation rate that CF inversion takes place at the end of the conical part formation of a boule.

For 1 angasite crystals a facial growth is characterictic. Crystals grown along the $Z$-axis have well developed $s 1 \%$ prism faces at its lateral surface.

It is necessary to consider the real structure and main defect types which can be inherent to a langasite crystal.

1. Sectorial inhomogeneity can occur when the crystallization front constitutes a complicated surface, consisting of regions of normal and of facial growth. The crystals with sectorial structure showed that facial growth regions have greater elementary cell parameter $\Delta Q=0,007 \AA$. For this reason residual stress $c a n$ appear in the crystal.

2. Short-term temperature fluctuations in the vicinity of the CF can cause striation along the crystal length if.e. regions with different coior, refraction indes and other characteristics).

3. Langasite crystals grown with 1 ow rotation rates have a growth column, a macrodefect, along the crystal, consisting of gaseous 
inclusions and microcracks. When natural convection predominates in the melt, voids (knags) can be formed within the conical part of the growing erystal.

The crystallografic investigation results of langasite crystals connected with correction of Wolf-Eragg-angular parameters of atomic planes in this material were also recelved. The finally obtained parameter value, are: $a=8,1783 \AA$ and $c=5.1014 \AA$ [4].

We have studied micro defects of grown langasite crystals by chemical etch method. Structural defects of 1 angasite are: dislocation slipbands, $p$ aces of dislocation exit at the surface of $Y$-and $Z$-cut plates. Differentiy inc ined dislocations, screw dislocations, platinum inclusions, point defects have been also observed (fig.2-10).

Langasite crystals can be successfully used in resonators and fi3ters for covering the pass band of $0,4-0,8 \%$ over a wide frequency range. Frequency-temperature characteristics of 1 angasite resonators and filtars have a form of a quadratic parabola with extremum in the region of the room temperature for zero-cut, at which the maximum value of electromechanical coupling factor is $18 \%$. Their change in the vicinity of zero cut has a gently sloping character. This evidences of the small compared with quartz crystal units dependence of FTC inflection point, of electromechanical coupling coefficient and frequency constant $(N)$ on the angle of cut $\alpha$. This fact simplifies manufacturing technology of langasite products. The steepness coefficient of FTC branches is $-7 \cdot 10^{-8}{ }_{0} C^{-2}$. Thus, as far as thermal stability of frequency is concerned, langasite resonators and filters are twice more stable than those of 1 ithium tantalate.

The mean resonance spacing value for langasite resonators is equal to $0,8 \%$ i.e. it is 3-4 times broader compared with that of the AT-cut quartz crystal units. The frequency coefficient value is $1380 \mathrm{kHz}$ which is 1,2 times smaller in comparison with AT-cut quartz crystal units. It is important to note, that parameters of Iangasite resonators and filters can be improved by employing optimum design and technology. From the data given it follows that these crystals have advantageous intermediate characteristics between those ofquartz crystal units and lithium tantalate resonators (table 1). 


\section{References}

[1] Fhilippot E., Ibanez A., A. Ibanez, A.Goiffon, A.Zarka, J.Schwartzel and J.Detain, "New approach of crystal growth and characterization of a quartz and berlinite isomorph: $\mathrm{GaFO}_{4}$ ", 45th IEEE Frequency Control Symposium, Hershey, 27-29 May $1992 \mathrm{pp} .744-752$

[2] Mill E.N." Eutachin A.B. et al." "Modified gallates with the structure $\mathrm{Ca}_{3} \mathrm{Ga}_{2} \mathrm{Ge}_{4} \mathrm{O}_{14}$ ". Feport of the USSR Academy of Science, 3 (1982) $\checkmark .271$ PP. $768-771$

[3] Kaminsky A.A., Mill E.M., Silvestrova I.M. et al." "Acoustic and electric properties of new neorganic material", Al-Union Acoustic Conference, NoEcow, 1983, p.20-22

[4] Gotalskaya A.M., Drezin D.I., Eezdelkin V.V.s V.N.Stassevich "Pecularities of technogy, physical properties and applications of new piezoelectric material langasite" s4th IEEE FrequencyControl symposium, Salt Lake City $1-3$ June 1993 pp. 339-347

[S] V.N.Stassevich "Single erystals technology", Moscow, Radio and Communication (1990) (in russian) 
Table 1. Fhysical and piezcelectric properties of langasite Erystals in comparison with quartz and lihtium tartal ate

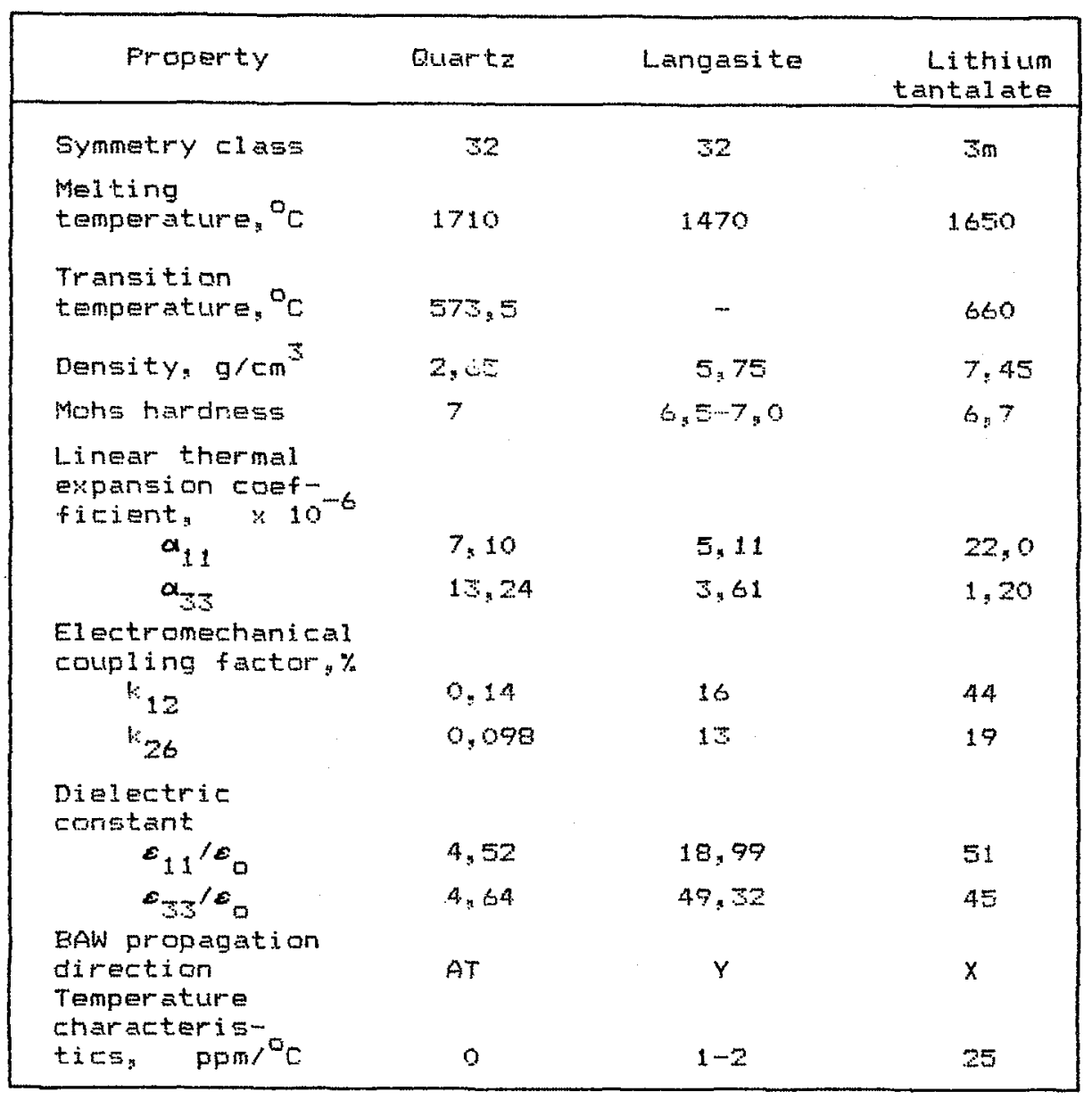




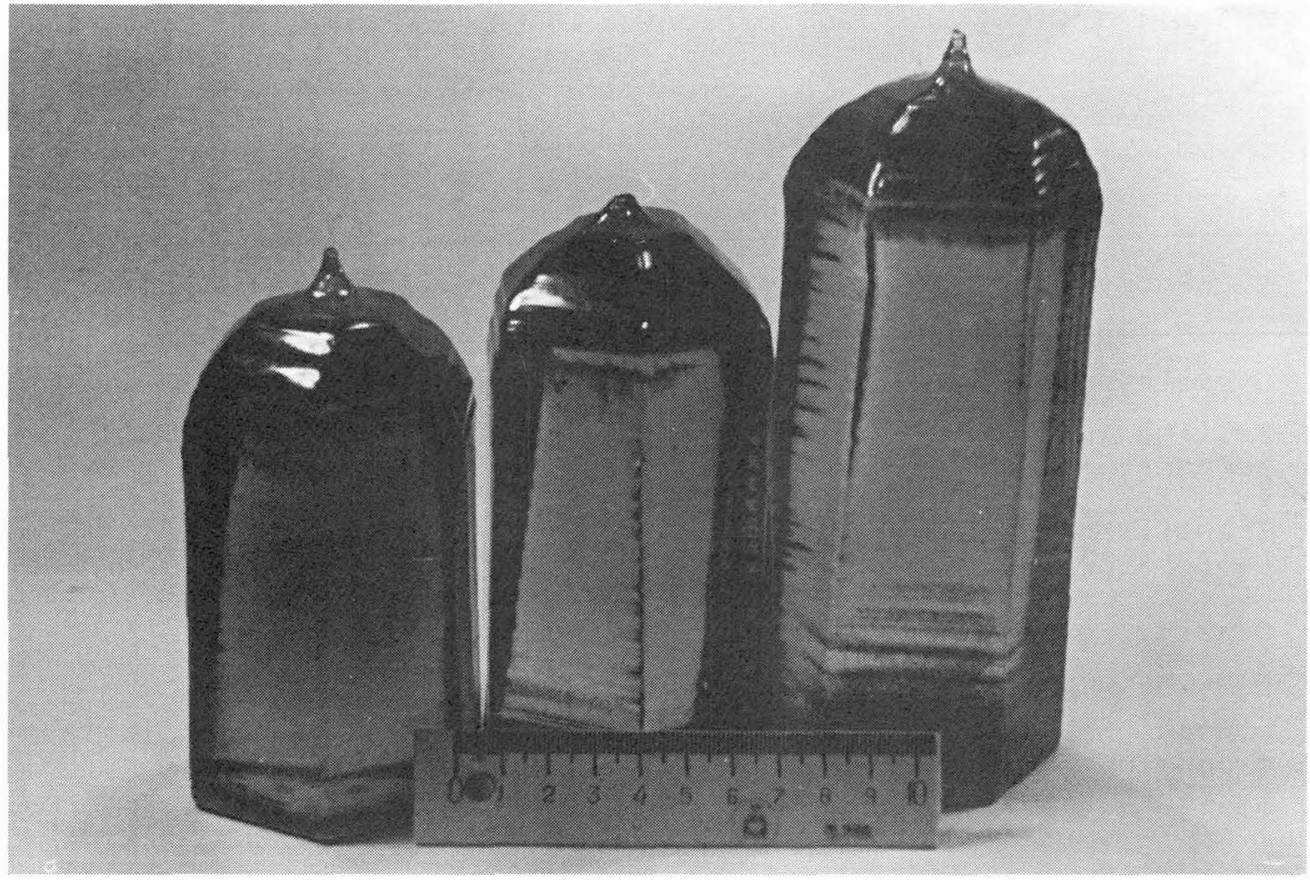

Fig. 1. "As grown" iangasite boules

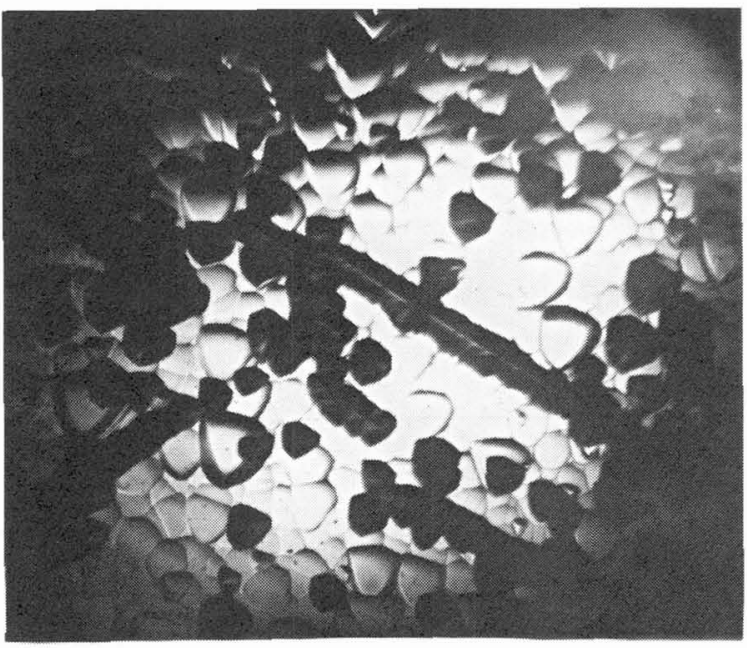

Fig. 2. Etch pits at places of dislocations and dislocation - Sliptand exit at the surface of z-cut plate (magnification $x 90$ ) 


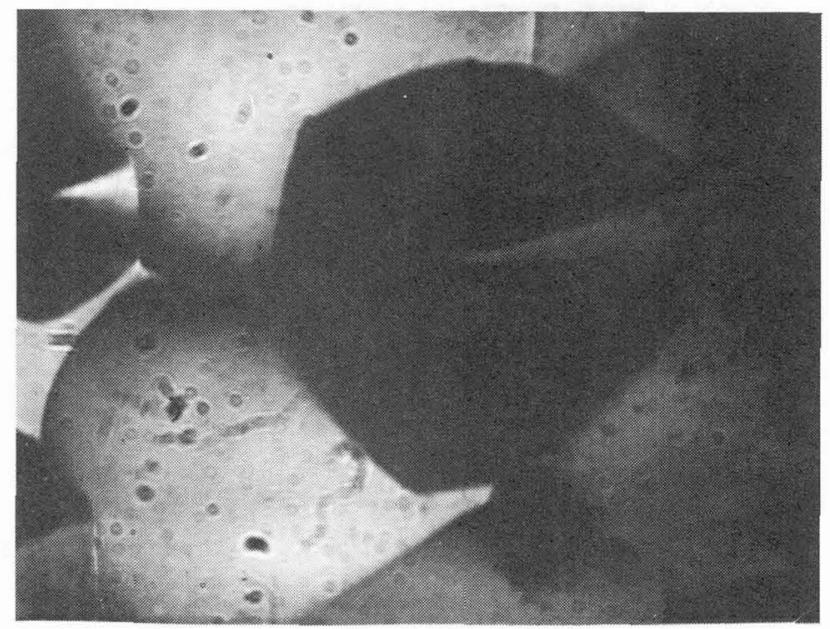

Fig. 3. Etch pit at the place of dislocation exit at the surface of z-cut piate sunder very strong magnification,

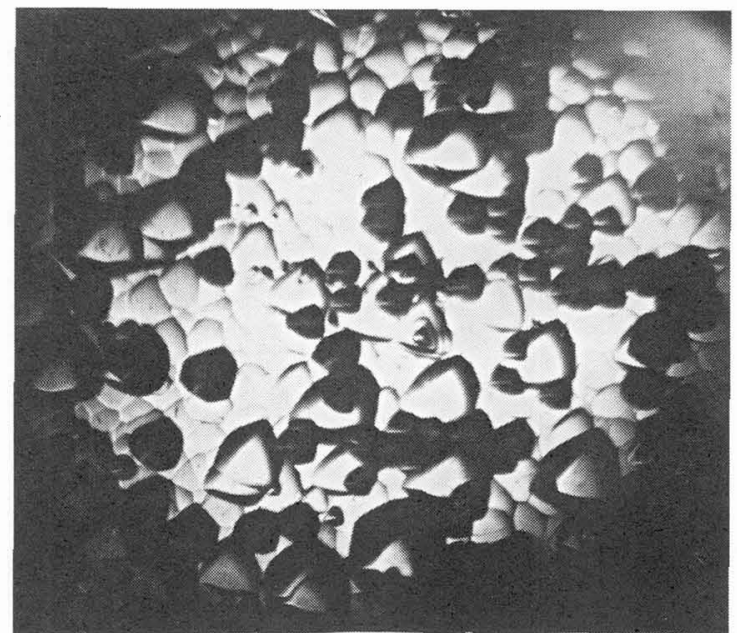

Fig. 4. Etch pits at places of dislocations with different inclination angle and screw (Burgers) dislocations exit at the surface of z-cut plate (magnification $\times 90$, 


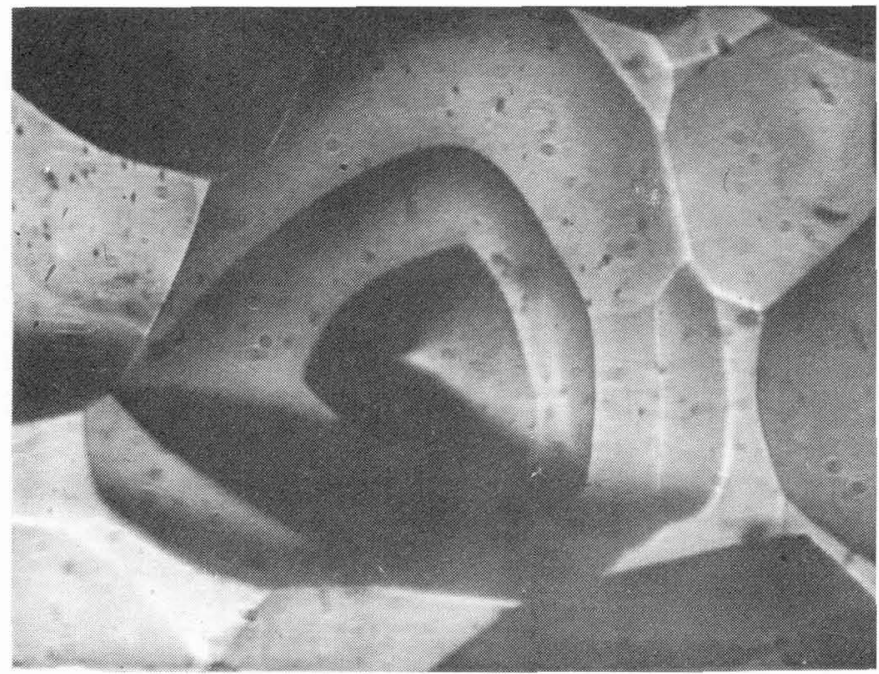

Fig. 5. Etch pit at the piace of screw dislocation exit at the surface of z-cut plate ( magnification $x$ 90)

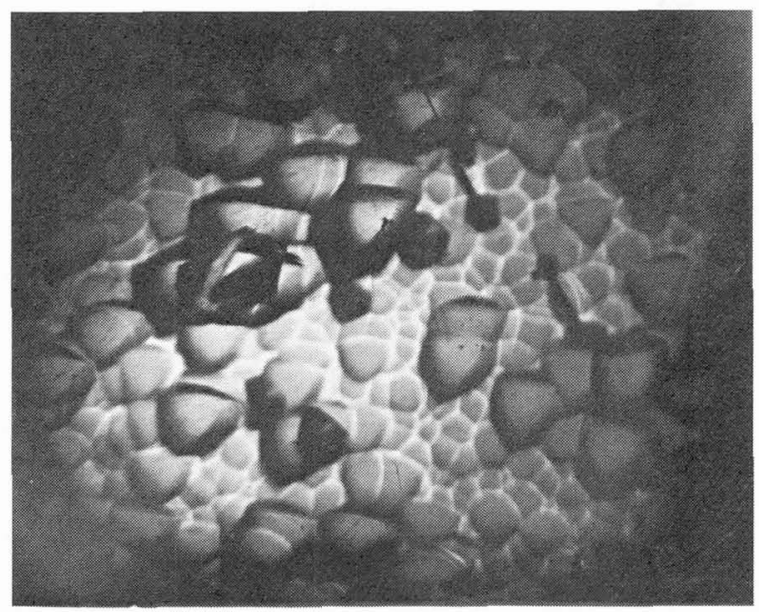

Fig. o. Etch pit having a form of a groove (beak-shaped) at the place of inclusion etching out at the surface of z-cut plate (magnification $x$ so ? 


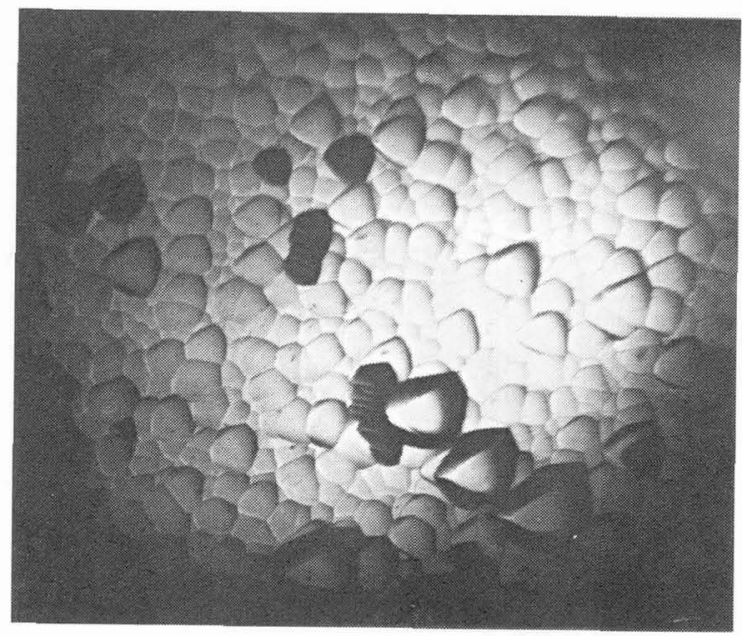

Fig. 7. Etch pits at placse of different inclination angle dislocations (slipbands) at the surface of plate z-cut (magnification $x 90$ )

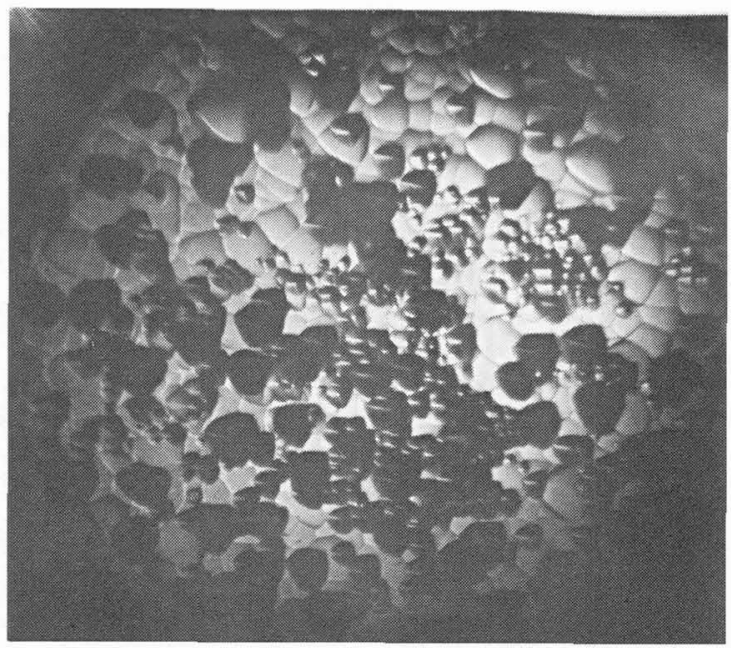

Fig. 8. Etch pits at place of dislocation and point defects (smaller ones) oxit at the surfaca of z-cut plate ( magnification $x 90$; 


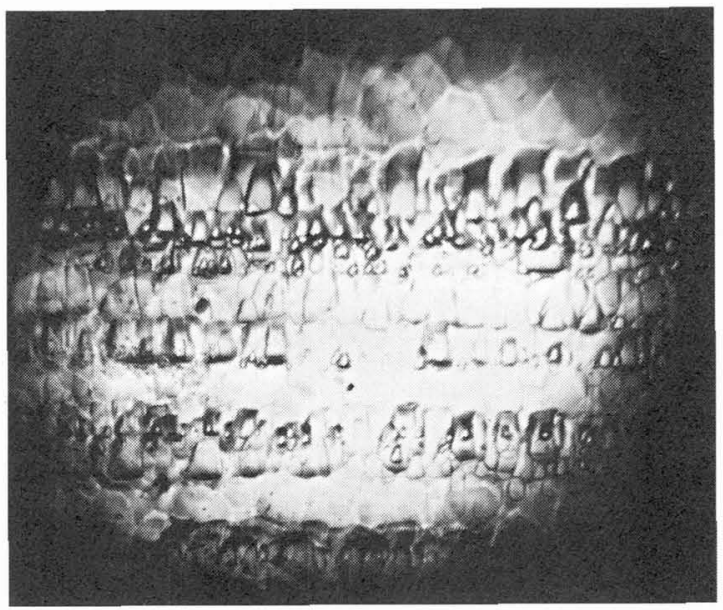

Fig. 9. Etch pits at the place of dislocation slipband exit at the surface of $Y$-cut plate (magnification $x 90$ ).

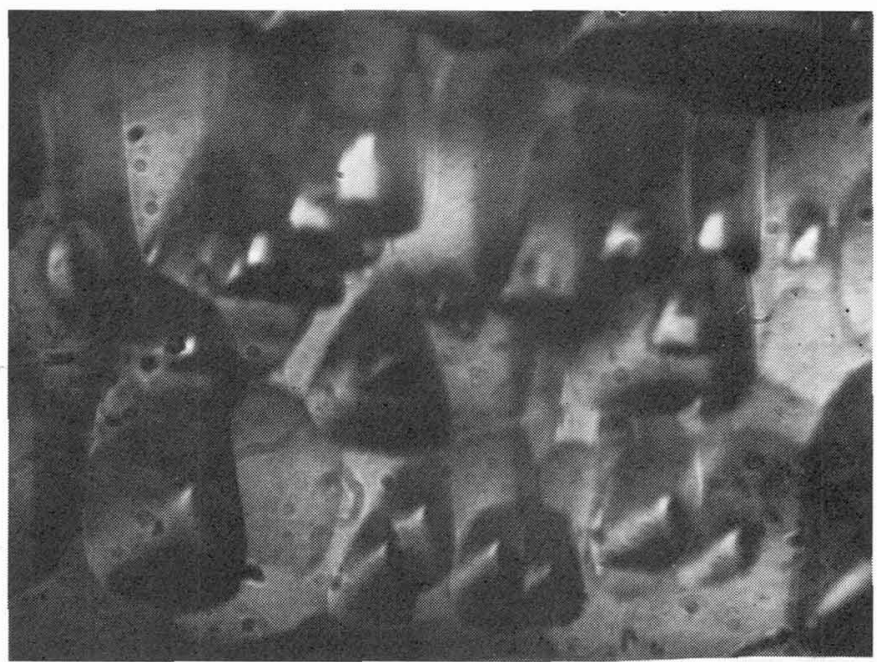

Fig. 10. Etch pits at places of dislocations exit at the surface of $Y$-cut plate (magnification $x$ 90) 